\title{
An Outpatient Approach to the Management of Recurrent Epistaxis in Patients with Hereditary Hemorrhagic Telangiectasia
}

${ }^{1}$ Vasilios Chalkiadakis, ${ }^{2}$ Silvestros Boukouvalas, ${ }^{3}$ Maria Manitsopoulou, ${ }^{4}$ Konstantinos Papadopoulos

${ }^{5}$ Georgios Karatzias

\begin{abstract}
Patients with Rendu-Osler-Weber syndrome, a relatively common inherited vascular disorder, usually appear with epistaxis. Treatment is supportive and conducive to the prevention of complications. There are several ways to manage this condition, including conservative, medical, or surgical/ procedural approaches.

Three cases of outpatients with hereditary hemorrhagic telangiectasia (HHT) are presented, who reported recurrent episodes of nasal bleeding. Furthermore, this study focuses on the approach to control episodes of epistaxis in our outpatient department, using radiofrequency (RF) energy in order to achieve coblation. Specifically, the clinical methodology aims to decrease the severity and frequency of nasal bleeding in the long term, with minimal local and general side effects. This will subsequently improve the quality of life in these patients.
\end{abstract}

Keywords: Coblation, Epistaxis, Hereditary hemorrhagic telangiectasia, Rendu-Osler-Weber.

How to cite this article: Chalkiadakis V, Boukouvalas S, Manitsopoulou M, Papadopoulos K, Karatzias G. An Outpatient Approach to the Management of Recurrent Epistaxis in Patients with Hereditary Hemorrhagic Telangiectasia. Int J Otorhinolaryngol Clin 2018;10(1):42-45.

Source of support: Nil

Conflict of interest: None

\section{INTRODUCTION}

Rendu-Osler-Weber syndrome, also known as HHT, has a prevalence of approximately 1 in 5,000 to 10,000, with a large geographic variability. ${ }^{1}$ The syndrome is inheri ted in an autosomal dominant manner with incomplete penetrance, although in $20 \%$ of cases, there is no family history. Many genes have been implicated with the syndrome, but the ENG in chromosome 9 seems to be the most significant.

\footnotetext{
${ }^{1,4}$ Otorhinolaryngologist, ${ }^{2,3}$ Resident, ${ }^{5}$ ENT Director

${ }^{1-5}$ Department of ENT, General Hospital "Asklipieio" Voulas Athens, Greece

Corresponding Author: Vasilios Chalkiadakis, Otorhinolaryngologist, Department of ENT, General Hospital "Asklipieio" Voulas, Athens, Greece, Phone: +00302132163000 , e-mail: chalkiadakis.v@gmail.com
}

Even though genetic tests are available, diagnosis is based on the Curacao criteria, established by the Scientific Division of the Hereditary Hemorrhagic Telangiectasia International Foundation. This condition is characterized by multiple telangiectases, spontaneous and recurrent epistaxis, visceral lesions, and the presence of a firstdegree relative with Rendu-Osler-Weber syndrome. ${ }^{2}$ The diagnosis is considered definite when three or more findings are present; possible or suspected when two findings are present; and finally, unlikely, when only one or none of these findings are present. The positive predictive value for a definite clinical diagnosis is 100\%, thus genetic tests are more essential in individuals with a possible clinical diagnosis of the syndrome. ${ }^{3}$ Clinically, telangiectases usually appear mucocutaneous with a very characteristic development. These often present in the nasal and gastric mucosa, on the lips, tongue, and fingers. Moreover, most patients exhibit larger arteriovenous malformations located in the hepatic, pulmonary, or cerebral vasculature.

Bleeding complications may arise from each arteriovenous malformation or telangiectasia. Spontaneous and recurrent epistaxis is the most common symptom in these patients. It affects up to $98 \%$ and most of them will have their first episode of nasal bleeding before the age of 20. ${ }^{4}$ Usually, these episodes are minimally bothersome, but in some cases, the severity might increase by time. Mucosal telangiectases have usually a cosmetic concern, whereas those in the gastrointestinal tract might cause chronic bleeding and iron-deficiency anemia. Pulmonary, hepatic, and cerebral vascular malformations are more important in terms of morbidity and mortality, although these are less common in individuals. Even though Rendu-Osler-Weber is a multisystemic syndrome, otolaryngologists may frequently be involved in order to control nasal bleeding.

There are multiple different options for the treatment of epistaxis in these patients. Most of the management decisions focus on bleeding complications. In the acute setting, clinicians usually proceed to anterior or posterior nasal packing with absorbable or nonabsorbable materials. Other options include conservative therapy, such as saline rinses, barrier creams, and topical emollients. ${ }^{5,6}$ 
Those therapies are considered as noninvasive, because the risk for the patient is minimal. Furthermore, medical therapies can be applied, such as antiestrogen drugs, bevacizumab, or timolol. ${ }^{7-9}$ When the bleeding episodes become more severe, even life-threatening, surgical options are considered. These procedural approaches include coagulation, coblation, septodermoplasty, embolization, or even nasal closure, known as the Young's procedure. ${ }^{10-12}$ These treatments aim at reducing the severity and the frequency of bleeding episodes and none of them has obtained full success. Furthermore, all these options come up with various risks for the patients, so a stepwise approach should be considered.

Within the last year, three patients previously diagnosed with HHT were referred in our clinic for recurrent episodes of nasal bleeding. The aim of this study is to describe our strategy for the management of epistaxis without the need of hospitalization. Our protocol is based upon coblation via RF energy, and in contrast to other medical centers, it is performed in an outpatient setting under local anesthesia, without intravenous sedation.

\section{CASE REPORT}

In our attempt to get a detailed picture of each patient, a complete medical history is followed by a thorough examination in order to underline all possible manifestation sites of the syndrome. According to the clinical findings and prior screening, blood testing, imaging, and echocardiogram are further recommended, in order to ensure that all severe arteriovenous malformations are found. Patients with suspected gastrointestinal bleeding are advised to take a gastrointestinal endoscopic investigation.

The method that we performed included firstly chemical coagulation using nitric acid solution under local anesthesia in order to locate the accurate site of telangiectasia in the nasal cavity. The subsequent stage was coblation via RF energy, which breaks down molecular bonds at low temperatures $(70 \mathrm{C})$. Telangiectasia cases were managed due to a RF generator with nonstick forceps in bipolar coagulation mode, at the lowest possible energy setting.

Patients were admitted for treatment sessions every 10 days. In general, three to four sessions were necessary for the complete management of each case. The patients were also encouraged through training courses to use on their own a local moisturizing and hemostatic ointment every day, for regular nasal mucosal care.

As mentioned earlier, three patients diagnosed with Rendu-Osler-Weber syndrome were recently treated by coblation via RF energy, for recurrent epistaxis. As noted in Figure 1, they all belong to the same family. Two of them are first-degree relatives, while the third one is a second-degree relative with one and a third-degree relative with the other. Until now, these three patients had no

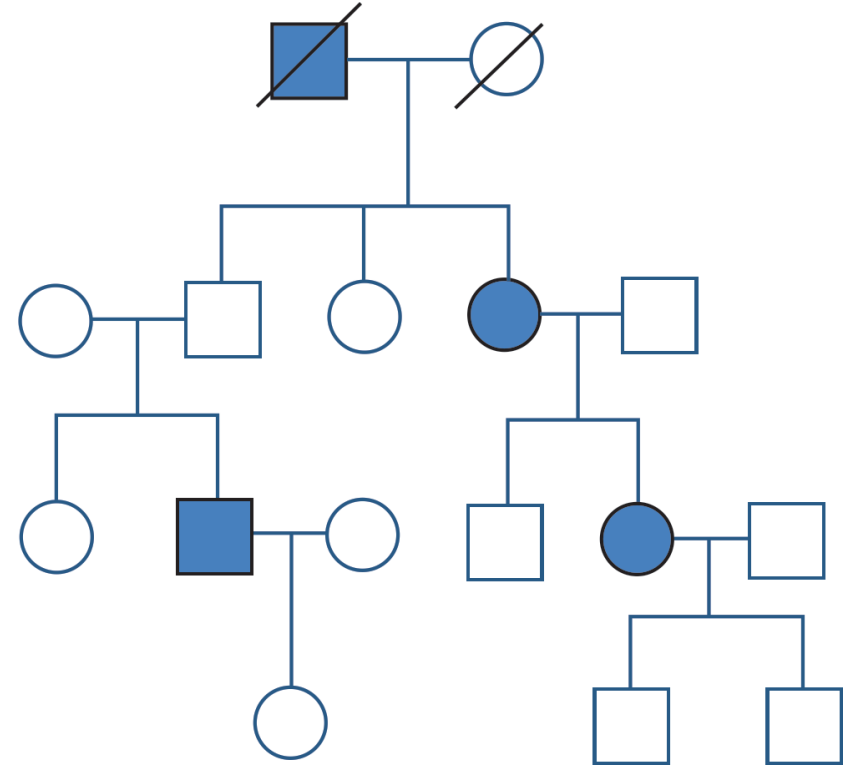

Fig. 1: A pedigree of a family with $\mathrm{HHT}$, a disease that is inherited with an autosomal dominant manner with incomplete penetrance

other treatment, except nasal packing and local ointments in order to control acute bleeding from the nose.

A 45-year-old female presented to our clinic with lifelong complications associated with Rendu-Osler-Weber syndrome. Her medical history revealed multiple telangiectases in the nasal mucosa, recurrent episodes of severe epistaxis, which occurred daily for a 2-month period and a family history of HHT. Furthermore, this chronic nasal bleeding contributed to iron-deficiency anemia, a common condition in these cases. No arteriovenous malformations were identified in the pulmonary, hepatic, or cerebral vasculature and gastrointestinal tract. For the management of these bleeding episodes, three treatment sessions were performed.

The second case is the 71-year-old mother of the individual described above. This patient presented with three Curacao criteria, including arteriovenous malformations in the gastrointestinal tract, classic telangiectases in the nasal cavity, and recurrent epistaxis. On physical examination, the patient reported systemic hypertension on medication and a previous episode of gastrointestinal bleeding due to a telangiectasia in duodenum. The patient referred several episodes of epistaxis, which were increased in frequency to 2 or 3 per month in the last 3 years. Four sessions were performed, in one of which, nasal packing for 48 hours was required.

Finally, the third patient presented with possible diagnosis of HHT. He experienced recurrent episodes of epistaxis in the last few years, associated with physical activity, as well as multiple nasal and oral mucosal telangiectasias. Interestingly, this 40 -year-old patient is nephew of the last patient mentioned (second-degree relative), and therefore first cousin of the primary case described (third-degree relative). The management 
strategy included three sessions, whereas nasal packing was also implemented once for 48 hours.

\section{DISCUSSION}

Hereditary hemorrhagic telangiectasia, also known as Rendu-Osler-Weber syndrome, is a relatively common systemic fibrovascular dysplasia, inherited in an autosomal dominant manner with incomplete penetrance. The major genes that have been identified are: ENG encoding endoglin (HHT type I), ACVRL 1 encoding activin receptor-like kinase (ALK-1) (HHT type II) and SMAD 4 encoding Smad 4 (HHT in association with juvenile poly posis). ${ }^{13,14}$ It is considered that over $80 \%$ of these patients will have mutations in the ENG or ACVRL 1 gene. ${ }^{15}$ This condition occurs in heterozygotes, while the homozygote form is not compatible with life. ${ }^{16}$

The mutated genes encode membrane glycoproteins which compose the transforming growth factor beta. All these functions are essential in angiogenesis. As a result, there is proliferation of endothelial cells, excessive vessel branching, and decreased recruitment of mural cells. This leads to the formation of telangiectasia, ${ }^{17}$ a systemic fibrovascular dysplasia. All these malformed vessels extend through the dermis and have excessive layers of muscle without elastic fibers, which is the basic defect in these patients. Due to this abnormal wall structure, these vessels are prone to spontaneous ruptures and injuries. ${ }^{18}$

Even though genetic tests are nowadays available, diagnosis remains clinical, based on the Curacao criteria. These criteria include not only the classic triad of recurrent and spontaneous epistaxis, multiple telangiectases at characteristic sites, and family history with an affected first-degree relative, but also the presence of large arteriovenous malformations, found in the gastrointestinal tract, or in the pulmonary, hepatic, spinal, and cerebral vasculature. The diagnosis is confirmed when at least three of these findings are present. Due to these important lesions in terms of mortality and morbidity, current guidelines recommend careful screening and close follow-up monitoring of all patients.

These individuals are at high risk for bleeding at the site of telangiectases or visceral lesions. The most frequent form of bleeding is epistaxis, affecting almost $100 \%$ of the patients. These nasal bleeding episodes are recurrent and the intensity of this symptom may range from minimally bothersome to life threatening. ${ }^{19}$ Furthermore, in some cases, this chronic bleeding may lead to iron deficiency anemia, or even multiple blood transfusions may be required. ${ }^{20}$

Nowadays, treatment is only supportive and the aim is to prevent any complications. Moreover, there is still no consensus for the best option. These options vary from conservative, medical, or surgical/procedural. Usually, majority of clinicians proceed to anterior-posterior nasal packing or cauterization when a bleeding episode occurs, although others prefer to manage the disease for as long as possible. In more severe cases, definitive treatment options are performed. These options include arterial embolization, laser, septodermoplasty, and nasal closure (Young's procedure). Because of the serious side effects, these options stand as the last resort that clinicians implement. ${ }^{21}$ Our treatment protocol is based on prevention of epistaxis through extensive information of patients, training courses for self-care, and also on a procedural control of mucosal telangiectases by coblation via RF energy.

In contrast to other medical centers, we perform this therapy in an outpatient setting, under local anesthesia without intravenous sedation. One significant benefit is that patients do not undergo the risk of recurrent general anesthesia, while this procedure is also time-effective for the individuals, as they are not hospitalized. ${ }^{22}$ Although the use of local anesthesia minimizes the pain level, there is a possibility for some patients to mention sensitivity at the site of intervention.

Another interesting advantage of this procedure is the lack of nasal occlusion by tape or packing. Even a nonpermanent closure of the nostrils could cause xerostomia, anosmia, sneezing, mucosal infection, and formation of crusts. Nevertheless, there is always the risk of rupturing arteriovenous shunts in the nasal mucosa during application or removal. ${ }^{23}$ Our personal experience showed that patients were very satisfied with this adjustment.

Furthermore, due to RF energy, coblation can be achieved at relatively low temperatures $(70 \mathrm{C})$, thus the risk of damaging the surrounding, healthy mucosa is minimized. ${ }^{24}$ In addition to this, thermal injury is decreased in the deeper layers of nasal mucosa, which leads to less crust formation. Besides, no relative scarring or septal perforation has been reported to date in our patients by the implementation of this regular therapy. ${ }^{25,26}$ Finally, follow-up of these three patients has shown that both the frequency and the severity of bleeding episodes have been reduced. Within the last 6 months, none of them has mentioned a new episode of epistaxis, while they all reported that with our approach, their quality of life has been improved.

\section{CONCLUSION}

Rendu-Osler-Weber syndrome is a multisystemic disease, characterized by the presence of vascular malformations. As a result, spontaneous and recurrent epistaxis is often reported in these patients. This may range from minimal bothering to life-threatening bleeding episodes. The majority of management decisions concern local complications caused by these episodes. Several procedural options are available for the treatment of nasal bleeding. Thus, it is critical that clinicians should be up-to-date in 
relation to these options in order to minimize the risk of septal perforation.

Our clinical practice showed that coblation via RF energy is a useful approach, because it may lead to minimal deep tissue thermal injury and less damage to the surrounding healthy mucosa. Furthermore, this management strategy appears to be time-effective, whereas it also eliminates the risks of recurrent general anesthesia. Finally, not only the frequency, but also the severity of nasal bleeding episodes were decreased; therefore, one may argue that the quality of life of patients who underwent this procedure has been improved.

\section{REFERENCES}

1. Sharathkumar AA, Shapiro A. Hereditary haemorrhagic telangiectasia. Haemophilia 2008 Nov;14(6):1269-1280.

2. Shovlin CL, Guttmacher AE, Buscarini E, Faughnan ME, Hyland RH, Westermann CJ, Kjeldsen AD, Plauchu H. Diagnostic criteria for hereditary hemorrhagic telangiectasia. Am J Med Genet 2000 Mar;91(1):66-67.

3. van Gent MW, Velthuis S, Post MC, Snijder RJ, Westermann CJ, Letteboer TG, Mager JJ. Hereditary hemorrhagic telangiectasia: how accurate are the clinical criteria? Am J Med Genet A 2013 Mar;161A(3):461-466.

4. Begbie ME, Wallace GM, Shovlin CL. Hereditary hemorrhagic telangiectasia: a view from the 21st century. Postgrad Med J 2003 Jan;79(927):18-24.

5. Faughnan ME, Palda VA, Garcia-Tsao G, Geisthoff UW, McDonald J, Proctor DD, Spears J, Brown DH, Buscarini E, Chesnutt MS, et al.; HHT Foundation InternationalGuidelines Working Group. International guidelines for the diagnosis and management of hereditary hemorrhagic telangiectasia. J Med Genet 2011 Feb;48(2):73-87.

6. Kara N, Spinou C, Gardiner Q. Topical management of anterior epistaxis: a national survey. J Laryngol Otol 2009 Jan;123(1):91-95.

7. Yaniv E, Preis M, Hadar T, Shvero J, Haddad M. Antiestrogen therapy for hereditary hemorrhagic telangiectasia: a double blind placebo controlled clinical trial. Laryngoscope 2009 Feb;119(2):284-288.

8. Riss D, Burian M, Wolf A, Kranebitter V, Kaider A, ArnoldnerC. Intranasal submucosal bevacizumab for epistaxis in hereditary hemorrhagic telangiectasia: a double blind, randomized, placebo controlled trial. Head Neck 2015 Jun;37(6):783-787.

9. Olitsky SE. Topical timolol for the treatment of epistaxis in hereditary hemorrhagic telangiectasia. Am J Otolaryngol 2012 May-Jun;33(3):375-376.

10. Jorgensen G, Lange B, Wanscher JH, Kjeldsen AD. Efficiency of laser treatment in patients with hereditary hemorrhagic telangiectasia. Eur Arch Otorhinolaryngol 2011 Dec;268(12): 1765-1770.

11. Ting JY, Remenschneider A, Holbrook EH. Management of severe epistaxis after Young's procedure: a case report. Int Forum Allergy Rhinol 2013 Apr;3(4):334-337.
12. Chin CJ, Rotenberg BW, Witterick IJ. Epistaxis in hereditary hemorrhagic telangiectasia: an evidence based review of surgical management. J Otolaryngol Head Neck Surg 2016 Jan;45:3.

13. Gallione CJ, Repetto GM, Legious E, Rustgi AK, Schelley SL, Tejpar S, Mitchell G, Drouin E, Westermann CJ, Marchuk DA. A combined syndrome of juvenile polyposis and hereditary haemorrhagic telangiectasia associated with mutations in MADH4 (SMAD4). Lancet 2004 Mar;363(9412):852-859.

14. Johnson DW, Berg JN, Baldwin MA, Gallione CJ, Marondei I, Yoon SJ, Stenzel TT, Speer M, Pericak-Vance MA, Diamond A, et al. Mutations in the activin receptor-like kinase 1 gene in hereditary haemorrhagic telangiectasia type 2. Nat Genet 1996 Jun;13(2):189-195.

15. Govani FS, Shovlin CL. Hereditary haemorrhagic telangiectasia: a clinical and scientific review. Eur J Hum Genet 2009 Jul;17(7):860-871.

16. Haitjema T, Westermann CJ, Overtoom TT, Timmer R, Disch F, Mauser H, Lammers JW. Hereditary hemorrhagic telangiectasia (Osler-Weber-Rendu Disease): new insights in pathogenesis, complications, and treatment. Arch Intern Med 1996 Apr;56(8):714-719.

17. Shovlin CL. Hereditary haemorrhagic telangiectasia: pathophysiology, diagnosis and treatment. Blood Rev 2010 Nov;24(6):203-219.

18. Pau H, Carney AS, Murty GE. Hereditary haemorrhagic telangiectasia (Osler-Weber-Rendu syndrome): otorhinolaryngological manifestation. Clin Otolaryngol Allied Sci 2001 Apr;26(2):93-98.

19. Fuchizaki U, Miyamori H, Kitagawa S, Kaneko S, Kobayashi K. Hereditary haemorrhagic telangiectasia (Rendu-Osler-Weber Disease). Lancet 2003 Nov;362(9394): 1490-1494.

20. Geisthoff UW, Schneider G, Fischinger J, Plinkert PK. Hereditary hemorrhagic telangiectasia (Osler's disease): an interdisciplinary challenge. HNO 2002 Feb;50(2):114-128.

21. Juares AJ, Dell'Aringa AR, Nardi JC, Kobari K, Gradim Moron Rodrigues VL, Perches Filho RM. RenduOsler-Weber syndrome: case report and literature review. Bras J Otorhinolaryngol 2008 May-Jun;74(3):452-457.

22. Folz BJ, Tennie J, Lippert BM, Werner JA. Natural history and control of epistaxis in a group of German patients with Rendu-Osler-Weber disease. Rhinology 2005 Mar;43(1):40-46.

23. Wirsching KE, Kuhnel TS. Update on clinical strategies in hereditary hemorrhagic telangiectasia from an ENT point of view. Clin Exp Otorhinolaryngol 2017 Jun;10(2):153-157.

24. Rotenberg B, Noyek S, Chin CJ. Radiofrequency ablation for treatment of hereditary hemorrhagic telangiectasia lesions: "how i do it". Am J Rhinol Allergy 2015 May-Jun;29(3): 226-227.

25. Joshi H, Woodworth BA, Carney AS. Coblation for epistaxis management in patients with hereditary haemorrhagic telangiectasia: a multicenter case series. J Laryngol Otol 2011 Nov;125(11):1176-1180.

26. Mortuaire G, Boute O, Hatron PY, Chevalier D. Pilot study of submucosal radiofrequency for epistaxis in hereditary hemorrhagic telangiectasia. Rhinology 2013 Dec;51(4):355-360. 